\title{
Development of the Cranfield University Bulldog Flight Test Facility
}

\author{
N.J. Lawson \\ n.lawson@cranfield.ac.uk \\ National Flying Laboratory Centre \\ Cranfield University \\ Cranfield, Beds MK43 OAL, U.K. \\ S.W. James \\ s.w.james@cranfield.ac.uk \\ Engineering Photonics \\ Cranfield University \\ Cranfield, Beds MK43 OAL, U.K. \\ G. Invers Rubio \\ g.inversrubio@cranfield.ac.uk \\ National Flying Laboratory Centre \\ Cranfield University \\ Cranfield, Beds MK43 0AL, U.K.

\section{Partridge \\ m.c.partridge@cranfield.ac.uk \\ Engineering Photonics \\ Cranfield University \\ Cranfield, Beds MK43 0AL, U.K.}

\author{
R. Correia \\ rng.correia@cranfield.ac.uk \\ Engineering Photonics \\ Cranfield University \\ Cranfield, Beds MK43 OAL, U.K. \\ J.E. Gautrey \\ j.e.gautrey@cranfield.ac.uk \\ National Flying Laboratory Centre \\ Cranfield University \\ Cranfield, Beds MK43 OAL, U.K. \\ S.E. Staines \\ s.staines@cranfield.ac.uk \\ Engineering Photonics \\ Cranfield University \\ Cranfield, Beds MK43 OAL, U.K. \\ R.P. Tatam \\ r.p.tatam@cranfield.ac.uk \\ Engineering Photonics \\ Cranfield University \\ Cranfield, Beds MK43 OAL, U.K.
}

\section{ABSTRACT \\ Cranfield University's National Flying Laboratory Centre (NFLC) has developed a Bulldog light aircraft into a flight test facility. The facility is being used to research advanced in-flight instrumentation including fibre optic pressure and strain sensors. During the development of the test bed, computational fluid dynamics (CFD) has been used to assist the flight test design process, including the sensor requirements. This paper describes the development of the Bulldog flight test facility, including an overview of the design and certification process, the in-flight data taken using the installed fibre optic sensor systems and lessons learned from the development programme, including potential further applications of the sensors.}

\section{NOMENCLATURE}

$\begin{array}{ll}\text { ADC } & \text { air data computer } \\ \text { AHRS } & \begin{array}{l}\text { attitude heading reference system } \\ \text { computational fluid dynamics }\end{array} \\ \text { CFD } & \begin{array}{l}\text { certification specification } \\ \text { CS }\end{array} \\ \text { EFFPI } & \text { extrinsic fibre Fabry Perot interferometer } \\ \text { FBG } & \text { Fibre Bragg grating } \\ \text { FSI } & \text { Fibre segment interferometry } \\ \text { IAS } & \text { indicated air speed } \\ \text { ISA } & \text { international standard atmosphere }\end{array}$




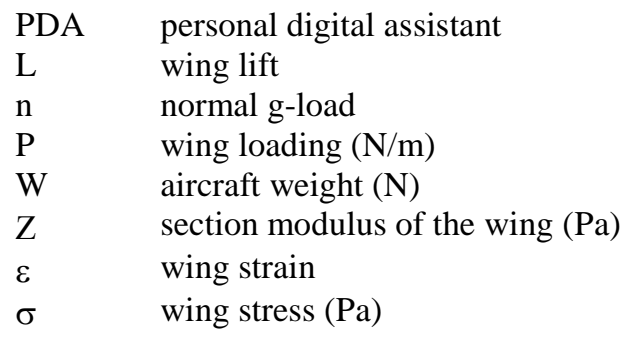

\subsection{INTRODUCTION}

The design and development of aircraft continues to present many challenges, including performance, aerodynamics, stability and control [1,2]. The nature of the problem is such that even advanced numerical methods $[3,4]$ still require forms of validation, which are usually based on measurements made in wind tunnels [5,6]. Ultimately, however, as it is not generally possible to attain the correct Mach number and Reynolds number simultaneously nor the appropriate turbulence level in a wind tunnel, the certification of aircraft requires a flight test programme [7,8]. It is also not uncommon for ongoing development and design issues to be addressed directly by a flight test, as the full scale aircraft will not have the scaling issues found in wind tunnels [9].

The difficulty of the flight test environment can lead to limitations in measurement methods and techniques, usually due to instrumentation access or the scale of the aircraft involved. Recently, European research programmes, with the authors' involvement, entitled Advanced In-Flight Measurement 1 and 2 (AIM and $\mathrm{AIM}^{2}$ ) have been addressing some of these problems by developing optical based methods for flight test applications [9]. Within the programme of work in AIM, one of the techniques, the image pattern correlation technique (IPCT), reached sufficient maturity to be tested successfully in-flight on an Airbus A380 aircraft, although there were many challenges reported, particularly with respect to access and imaging geometries [9]. In the follow-up project $\mathrm{AIM}^{2}$, further techniques based on optical fibres were flight tested. The use of these new techniques was aimed at addressing a number of the limitations of the other camera based techniques. An overview of the deployment of these measurement systems and the associated flight tests on a Scottish Aviation Bulldog light aircraft in $\mathrm{AIM}^{2}$ will be presented in the following sections, along with a discussion of lessons learnt from the recent flight test programme.

\subsection{DEVELOPMENT OF BULLDOG FLYING TEST BED}

\subsection{Fibre Optic Measurement Methods for Flight Test}

The $\mathrm{AIM}^{2}$ programme was focused on the development and application of advanced measurement techniques for use during flight tests [10-12]. Instrumentation development for flight tests has been ongoing and formally documented since the 1950's in the form of the AGARD and RTO Flight Test Instrumentation Series, AGARDograph 160 [13,14]. In particular, optical fibre based methods are now gaining importance and maturity for flight tests as highlighted in recent applications and testing [15,16]. Optical fibre based measurement methods offer high sensitivity with minimum signal loss from multiple measurement points, over large distances and without any electromagnetic compatibility 
(EMC) restrictions. Of the most successful recent optical fibre-based applications reported by NASA [16], the measurement of surface strain on aircraft wings using with fibre Bragg gratings [FBGs] allowed the in-flight measurement of wing shape at sample rates potentially high enough to allow incorporation into a future flow control system. The measurement of pressure with FBG methods has received less attention, as the packaging for multiple point measurement of pressure along a single fibre has not yet allowed the sensitivity required to be attained [17]. An alternative method, however, for the measurement of pressure with an optical fibre is the extrinsic fibre Fabry-Perot interferometer (EFFPI) [18,19]. This method offers high sensitivity, but with only a single measurement point on each fibre. However, to the best of the authors' knowledge, this paper presents a seminal application of an EFFPI method for flight test.

The principle of FBG sensors relies on the measurement of the wavelength change of the light reflected by a grating structure fabricated within the core of an optical fibre [20,21]. Under local strain, the grating period changes, perturbing the reflected, Bragg, wavelength from which the surface strain can be measured at the grating's location (typically with a gauge length of order 1-5 mm). A number of FBG strain sensors can be multiplexed within a single optical fibre by fabricating each grating with a different period, resulting in each reflecting a different wavelength. The physical separation of the gratings is arbitrary, allowing a high density of measurements in regions of high strain gradient, and sparse measurements over larger distances. By using a suitable sensor interrogator system, typically involving the use of a laser, the wavelength of which is scanned rapidly across a spectral range of order 10s of $\mathrm{nm}$, and a photodiode, a number of measurement points can then be interrogated simultaneously at sample rates of typically $1 \mathrm{~Hz}-20 \mathrm{kHz}$. Even for fibres with lengths of hundreds of metres, there is negligible degradation of the FBG signal making the system suitable for monitoring surface strain over both small and large aircraft structures. Furthermore the optical fibres have minimal footprints as their diameter are typically around $0.15 \mathrm{~mm}$. Figure 1 shows an image of a typical FBG used for this project.

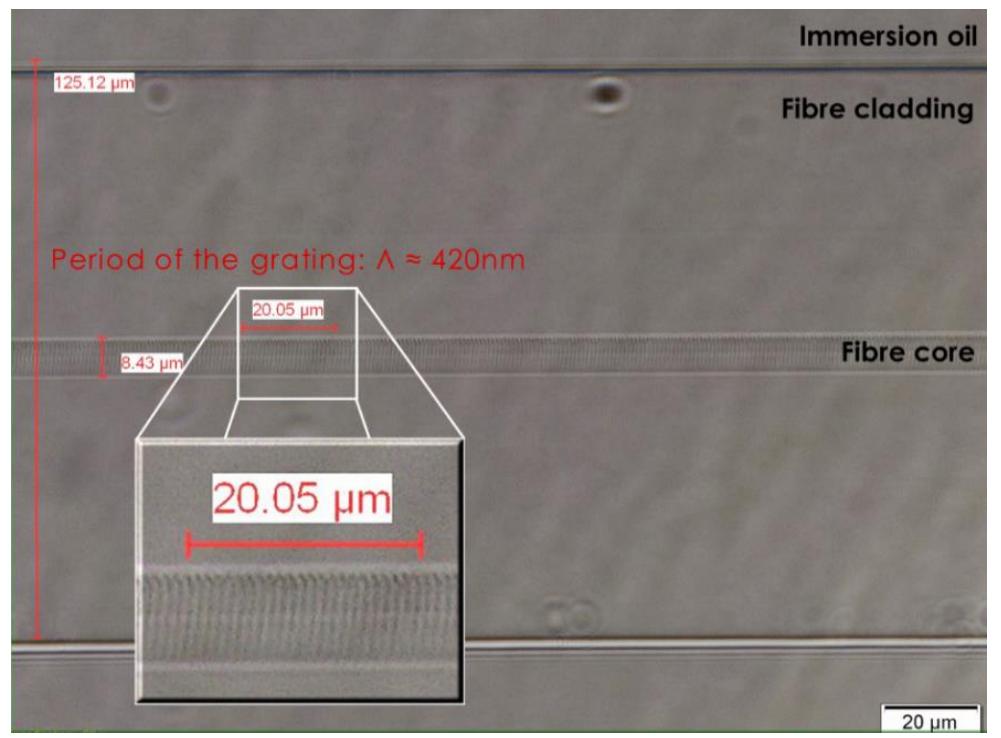

Figure 1. Image of a typical fibre Bragg grating used for the measurement of surface strain 
The EFFPI method is based on the interference signal generated from light reflected at the sensor head. Light traveling down the fibre is partially reflected at the fibre tip while a portion of the light emitted from the fibre is reflected from a reflective membrane located above the tip and is coupled back into the optical fibre. The interference between these two beams provides a signal that is dependent on the separation between the fibre tip and the sensing membrane $[18,22]$. As the local static pressure deforms the membrane, change in the phase of the interference signal proportional to the applied pressure is observed. Using interrogation hardware similar to that used to monitor FBG sensors, the spectrum of the reflected signal can be measured and decoded using a calibration factor that is directly proportional to the static pressure at the membrane. By choosing a suitable membrane, dynamic pressure can be monitored at the sensor tip. The diameter of an EFFPI sensor can be $<1 \mathrm{~mm}$, offering the possibility of dynamic pressure measurement with sensor dimensions that are equivalent or smaller than those of existing Kulite sensors, but without the issues associated with electrical installation, as optical fibre downleads of lengths of many tens of metres can be used with minimum signal loss. Dynamic responses better than $10 \mathrm{kHz}$ are also possible from an EFFPI sensor [19]. Figure 2 shows a schematic of the EFFPI sensor developed for this project.

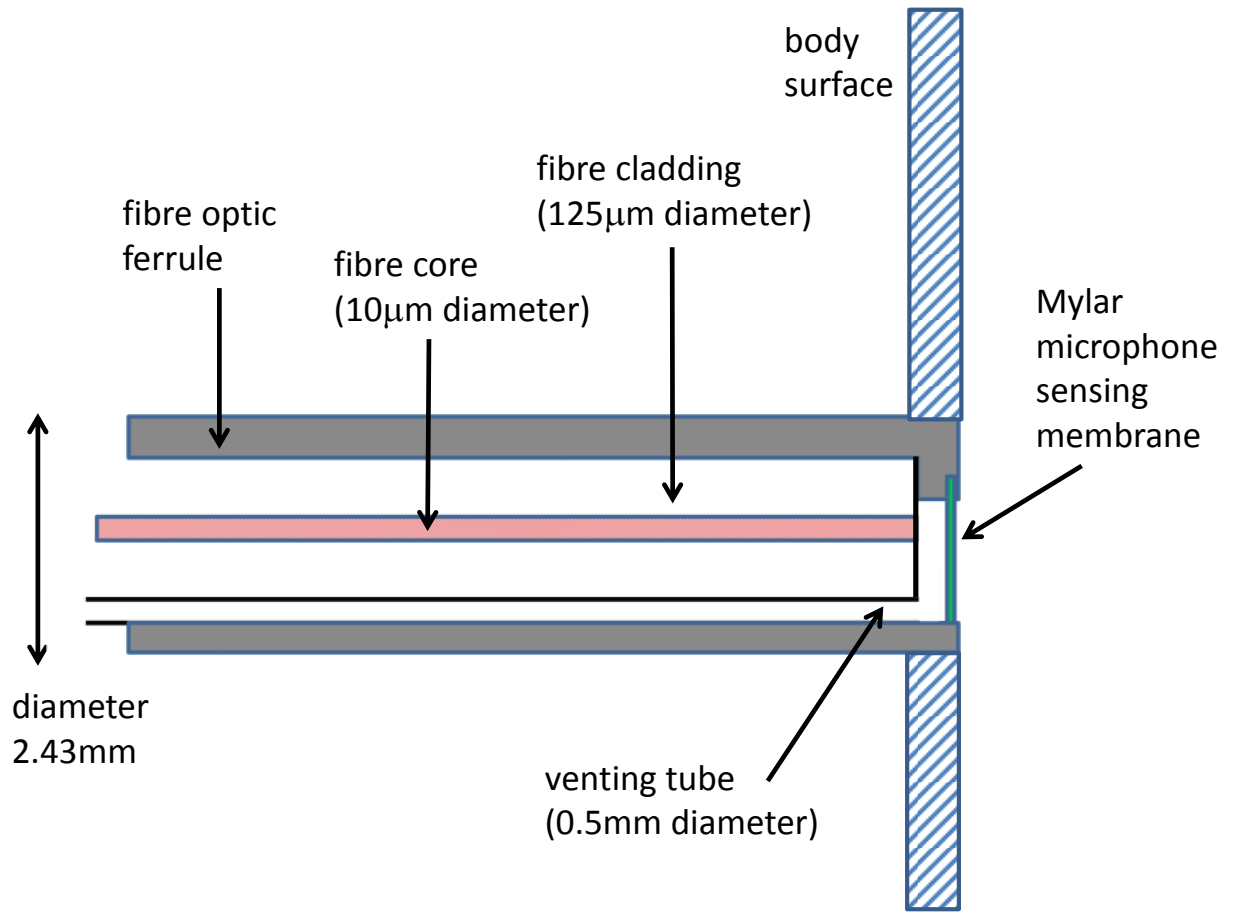

Figure 2. Schematic of an extrinsic fibre Fabry Perot Interferometer (EFFPI) static pressure sensor

The following section describes the development, certification and flight testing of these two fibre optic sensing technologies, namely FBGs for the measurement of strain on the wing surface and EFFPI for the measurement of unsteady static pressure. 


\subsection{Laboratory Development of the Fibre Optic Techniques}

Before the FBG and EFFPI systems were flight tested, a period of laboratory development and testing was carried out to determine the optimum packaging and mounting methods for the two types of sensors. In the laboratory tests, both sensors were interrogated using a system consisting of a wavelength tuneable laser, a set of optical detectors and directional couplers and a National Instruments PXI acquisition board. Details of this set-up are provided in reference [23].

For the FBG sensors, techniques for attaching the optical fibre onto the painted surface of the Bulldog wing were investigated. This involved adhering FBGs, fabricated in-house in hydrogen loaded SMF 28 fibre onto several test plates using a number of different adhesives including two part araldite and cyanoacrylate. The $0.9 \mathrm{~mm}$ thick test plates with dimensions $25 \mathrm{~mm} \times 200 \mathrm{~mm}$ were fabricated from scrap aluminium taken from aircraft skin similar to that of the Bulldog. Each test plate was loaded mechanically using an Instron mechanical test bench. Test plates with two surface finishes were used, painted and stripped of paint, with the aim of establishing the influence of the paint on the transfer of strain to the FBG. From the initial tests, the best performance was obtained using cyanoacrylate glue, and the effect of the paint on the strain transfer to the FBG was found to be negligible. A conventional resistive foil strain gauge (RFSG) was mounted adjacent to the FBG on the painted sample and the test repeated to calibrate the FBG. This was found to be $0.8296 \mu \varepsilon / \mathrm{N}$, compared to $0.8321 \mu \varepsilon / \mathrm{N}$ for the RFSG, with full scale linearities and repeatabilities of $0.29 \%$ and $0.41 \%$, respectively, over a calibrated range of $600 \mu \varepsilon$.

The development of the EFFPI sensor involved fabrication of prototypes, characterisation in the laboratory and finally deployment on a model in a wind tunnel, before the sensor was fitted onto the aircraft for the flight test. To simplify fabrication, the design of the EFFPI sensor head was based on a commercially available microphone membrane made from electret metallised Mylar film. With reference to Figure 2, the optical fibre was terminated within a ceramic ferrule of the type used in FC/PC fibre optic connectors, and the end face polished. The ceramic ferrule had been machined parallel to its long axis to create a " $\mathrm{D}$ " shape. The ferrule was inserted into a zirconia sleeve, to the end of which the membrane had been attached. A reference pressure tube was inserted into the space between the " $D$ " shaped ferrule and the sleeve. The reference tube permitted the cavity between the ferrule and the end of the optical fibre to vent, therefore allowing the membrane to measure a relative pressure. The reflection spectrum from the EFFPI was monitored was the ferrule was inserted into the sleeve to allow the required cavity length had been achieved, whereby 11 cycles of the characteristic channel spectrum were visible over a wavelength range of $50 \mathrm{~nm}$, corresponding to a cavity length of $16.5 \mu \mathrm{m}$.

The EFFPI sensor was calibrated using a Druck DPI610 pressure calibrator, demonstrating linearity and a resolution better than $0.2 \mathrm{~Pa}$ over a test range of $400 \mathrm{~Pa}$. Further tests using a loudspeaker showed the sensor to have good dynamic pressure response at frequencies in access of $10 \mathrm{kHz}$ by comparing the speaker input to the sensor response. The details of the wind tunnel tests are provided in [24] and showed the EFFPI sensor to have sufficient sensitivity for the pressure range expected in the flight test. These additional tests also showed the sensor to be robust under similar aerodynamic conditions. 


\subsection{Scottish Aviation Bulldog Test Bed Certification}

The aircraft chosen for the fibre optic flying test bed was a Scottish Aviation Bulldog registration G-BCUO. The Bulldog is a two seat aerobatic category light aircraft. The Bulldog modifications were completed as part of a European FP7 research project entitled 'Advanced In-flight Measurement $2\left(\mathrm{AIM}^{2}\right)$, EU contract number 266107 [see website: aim2.dlr.de].

Early on in the project it was decided that the flight tests would be flown with the Bulldog aircraft certified instead of on a permit basis. This requirement for certification would allow the aircraft to continue to be used as an aerobatic trainer as well as a flying test bed. This certified basis is much less restrictive than if the aircraft was flight tested on a permit, whereby the carriage of passengers and the approved flight envelop can be significantly restricted. Based on European Aviation Safety Agency (EASA) regulations, the Bulldog is an Annex II, non-EASA aircraft.

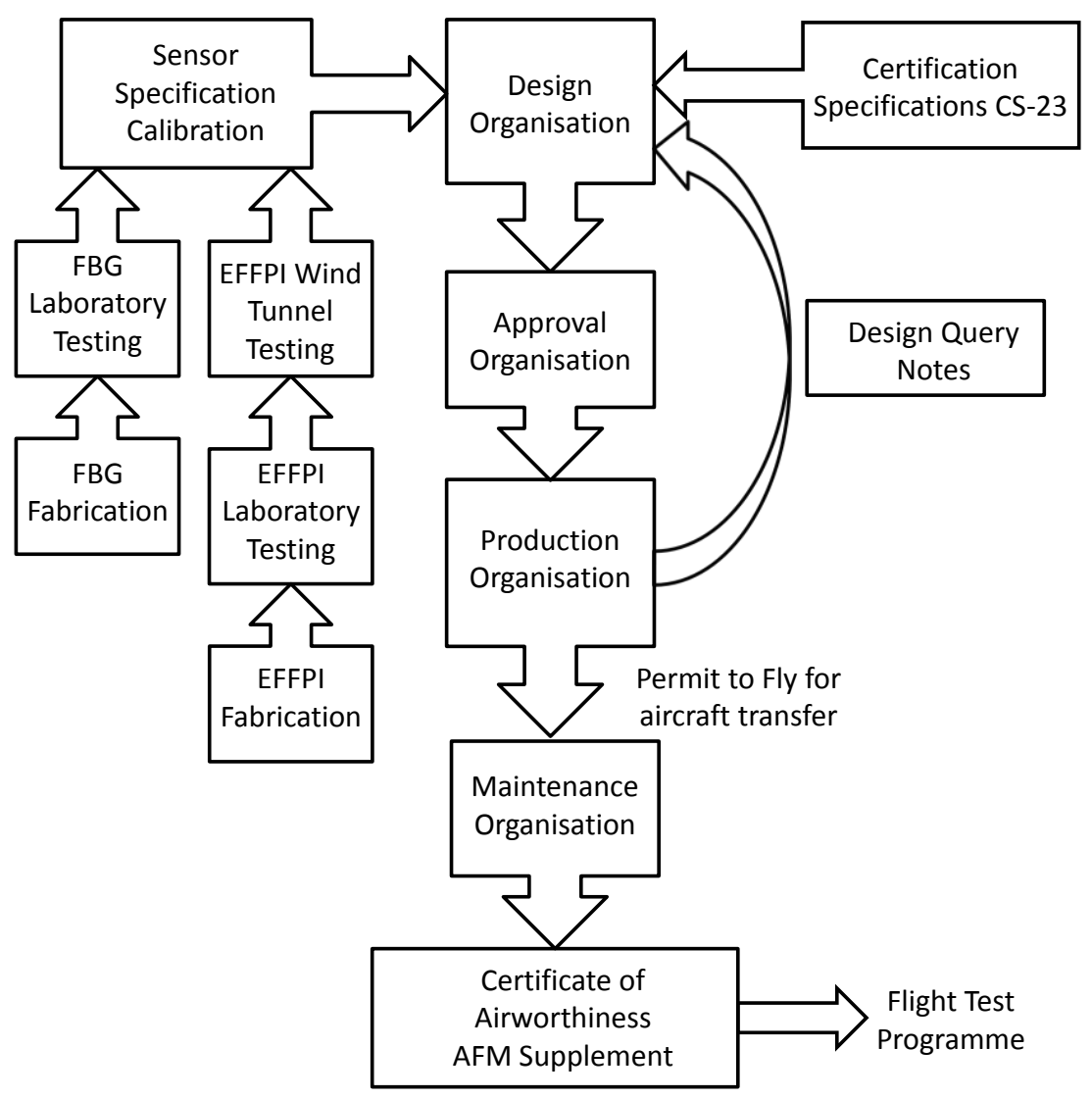

Figure 3. Bulldog certification and modification process 
The modification process (see Figure 3), based on Certification Specification 23 [25] rules, took place over two years and involved four subcontractor companies with the following functions: Design Organisation, Approval Organisation, Manufacturing / Aircraft Fitting Organisation and Maintenance Organisation, with Cranfield University acting as the project leader. Given that the modification was classified as minor, this arrangement was a significant management challenge for Cranfield University and took a disproportionate amount of time when compared to the time to fit the aircraft. One reason for the large number of parties was that because the Bulldog is an Annex II non-EASA aircraft [26], the aircraft had to be certified under national U.K. regulations. Unfortunately, there are a decreasing number of companies in the U.K. who have national approvals for Annex II aircraft such as the Bulldog. Therefore although Cranfield University could find numerous companies to design under EASA approvals, an additional company with national approvals was required to approve any designs completed by the Design Organisation.

During the manufacture and fitting process, a further feedback loop occurred whereby the Manufacturing / Fitting Organisation could submit design query notes (DQNs) to the Design Organisation. In any aircraft modification process, this is a common means by which simple design changes can be incorporated into the fit of the aircraft with final approval, before the aircraft is released for certification. The nature of flight test modification on legacy aircraft will always require this DQN feedback process, as the designers cannot always obtain sufficient information on the aircraft at the time the drawings are compiled.

The final certification process was further complicated in that the approved Maintenance Organisation was also a separate company based at Cranfield. The Maintenance Organisation was required to issue the Airworthiness Review Certificate (ARC), incorporate the aircraft flight manual (AFM) supplements and issue a certificate of release to service (CRS) as part of the requirement for final aircraft airworthiness. Therefore, as the manufacture and fitting of the modification was completed in a different location to the maintenance organisation, on completion of the modification, a national permit to fly was issued under British Civil Aviation Regulations (BCAR) the Manufacturing / Fitting Organisation. This permit to fly, with certain restrictions, allowed the Bulldog to be transferred back to Cranfield, where the Maintenance Organisation could issue the final certification documents.

\subsection{Scottish Aviation Bulldog Test Bed Description}

Figure 4 shows the general layout of the fibre optic systems deployed on the Bulldog flight test bed, where one optical fibre (SMF 28) containing an array of 5 wavelength-division multiplexed FBGs was secured to the top of the wing along the wing spar. 4 of the FBGs, attached to the surface of the wing using cyanoacrylate, were used to measure strain, while the $5^{\text {th }}$ FBG was housed in a hypodermic tube such that it measured only the temperature, and was used for temperature compensation. The EFFPI sensor was positioned behind the cockpit on a removable test plate. This test plate had been installed on a previous flight test programme and therefore significantly simplified the design and certification process. A Kulite unsteady pressure sensor was fitted adjacent to the fibre pressure sensor for validation of the measurements made by the EFFPI sensor.

Although the use of the test plate on which the pressure sensors were mounted simplified the certification process, from an aerodynamic point of view this was not an ideal choice for the positioning of the sensors, as no aerodynamic data was available on this area of the Bulldog. 
Integrating the pressure sensors on, for example, a section of the wing would have allowed the use of published pressure data for comparison. However, this would have substantially complicated the certification process. Therefore, it was decided that this problem would be addressed by aerodynamic measurements on a 30\% scale wind tunnel model of the Bulldog, combined with a full scale computational fluid dynamics (CFD) model. These measurements and CFD model are described in a further publication [24].

The Bulldog modification included the following installations:

- $\quad$ Power supply box $(0.36 \mathrm{~kW})$

- UEI data logging cube + trigger box

- $\quad$ SBG Systems SBG Systems IG-500A-G4A2P1-B AHRS

- Smart Fibres SmartScan Aero fibre Bragg grating interrogator;

- An optical fibre containing 5 FBGs mounted onto the upper wing surface;

- An EFFPI sensor mounted onto a fuselage test plate;

- A XCQ-093 Kulite pressure sensor mounted onto the EFFPI test plate

- An on-board cockpit mount and camera

In addition to the installed equipment, a Druck DPI 740 barometer and a PDA were taken as carry on equipment to allow a cockpit reference pressure to be recorded throughout the flight, to monitor the effect of ambient conditions and to allow the performance of precise straight and level manoeuvres at a fixed pressure altitude. Figure 5 shows the installed equipment in the cockpit and Figure 6 shows the arrangement used to feed the optical fibres through the fuselage, for the FBG sensors attached to the wing and the pressure sensor located behind the cockpit.

The optical fibre lead connected to the FBG sensors was fed through the side of the fuselage and onto the edge of the wing using hypodermic tube mounted into a solid plate. Each FBG was attached to the wing cyanoacrylate adhesive and the entire length of fibre on the wing covered with $3 \mathrm{M} 425-50$ aluminium speedtape. This was approved for use up to the $\mathrm{V}_{\mathrm{NE}}$ of the aircraft which is 185 knots.

The optical fibre connecting the interrogator to the EFFPI pressure sensing head was passed through the rear cockpit bulkhead and loomed along the side of the fuselage to the pressure test plate. For both the EFFPI pressure sensor and the Kulite pressure sensor, a reference pressure port was installed onto the same fuselage loom and fed back into the cockpit where the Druck barometer was used to monitor the pressure throughout the flight. Final validation of the operation of the FBG strain system was undertaken prior to the first flight by comparing the FBG measurements to conventional strain gauges mounted adjacent to the fibre optic. These additional strain gauges were then disconnected for the subsequent flight tests.

Following the modifications to the aircraft, there was no significant change in the centre of gravity, but the weight increased by approximately $11 \mathrm{~kg}$, with a maximum take-off weight of $1066 \mathrm{~kg}$. There were no limitations placed on the original aircraft flight envelope, which as an aerobatic category aircraft includes a permitted $g$-load range of $-3 \mathrm{~g}$ to $+6 \mathrm{~g}$.

The uncertainties of the measurements provided by the fibre optic sensors was assessed in the laboratory prior to flight test, using calibration procedures at fixed and varying 
temperatures. The uncertainty of other sensors including the cockpit instruments was referenced from either manufacturer's datasheets or the aircraft flight manual. Table 1 summarises the performance and range of all the relevant sensors tested in the laboratory and used for the flight test.

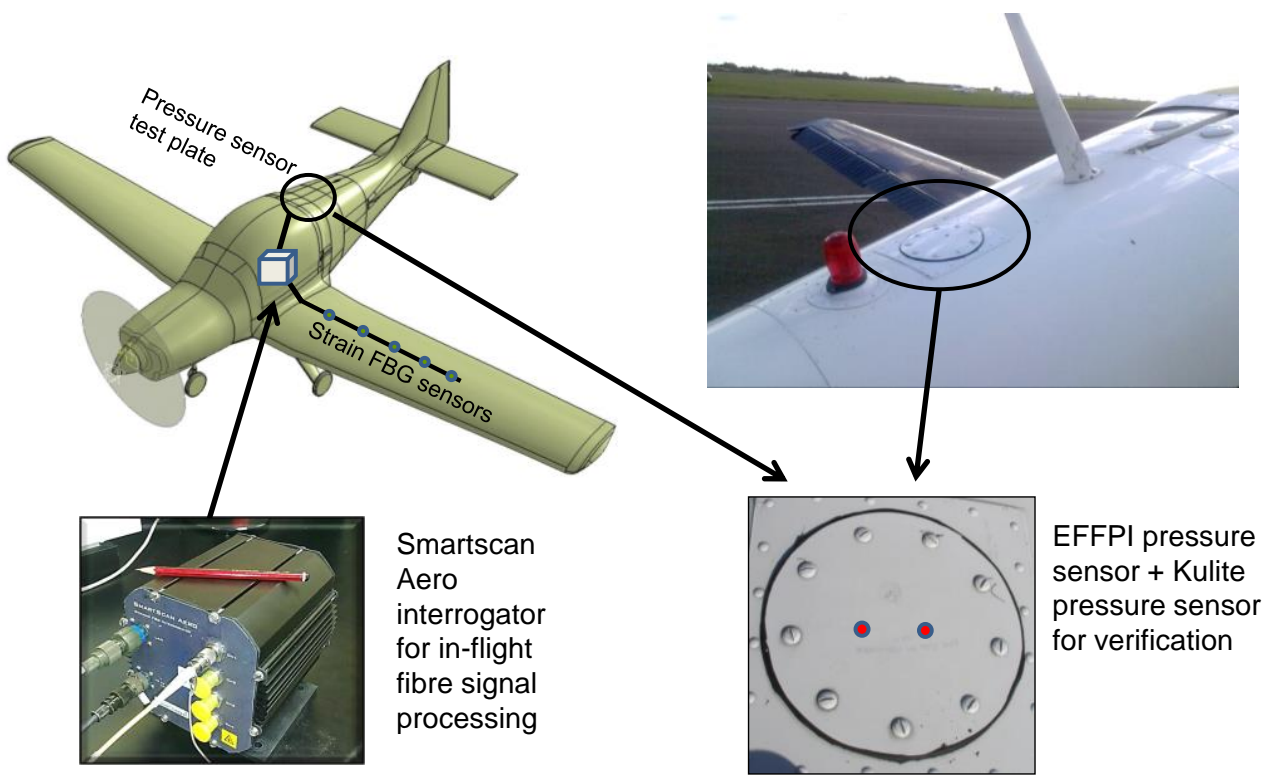

Figure 4. Schematic of the Bulldog showing the general layout of the fibre optic systems.

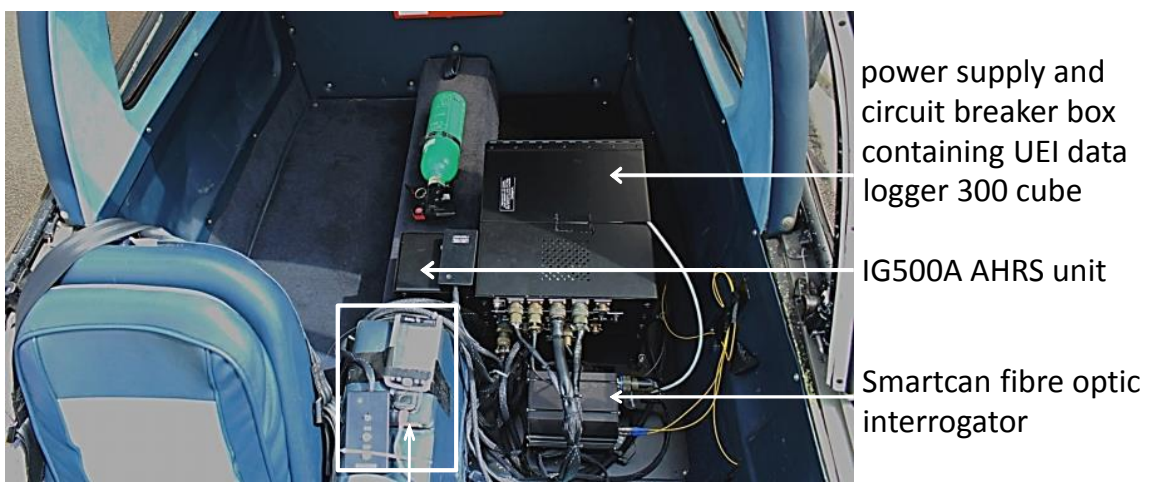

Trigger box and Druck reference pressure barometer

Figure 5. Annotated image of the Bulldog cockpit installation. 


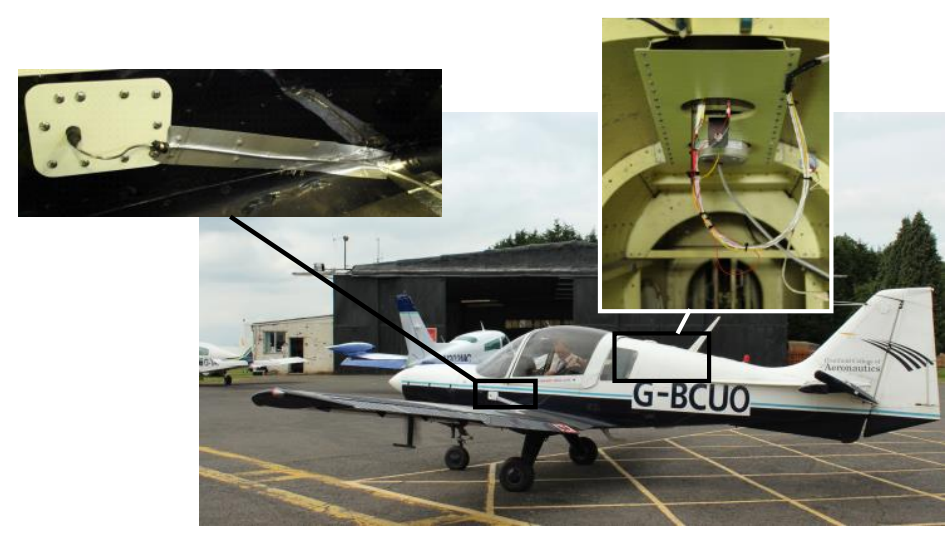

Figure 6. Image of the Bulldog showing the routing of the fibre optic systems through the fuselage.

Table 1. Summary of sensor performance, range and resolution.

\begin{tabular}{|c|c|c|c|}
\hline Sensor & Resolution & $\begin{array}{l}\text { Tested } \\
\text { Range }\end{array}$ & Notes \\
\hline $\begin{array}{l}\text { Fibre optic FBG } \\
\text { strain sensor }\end{array}$ & $0.29 \%$ of full scale & $\begin{array}{l}600 \\
\text { microstrain }\end{array}$ & $\begin{array}{l}\text { Temperature compensated } \\
\text { from in-situ unstrained FBG }\end{array}$ \\
\hline $\begin{array}{ll}\text { EFFPI } & \text { pressure } \\
\text { sensor } & \end{array}$ & $\begin{array}{l}0.33 \% \text { of full scale } \\
\text { (laboratory system) } \\
+/-2.15 \%-4.92 \% \text { of } \\
\text { full scale depending } \\
\text { on temperature (flight } \\
\text { test system) }\end{array}$ & $\begin{array}{l}400 \mathrm{~Pa} \\
10,000 \mathrm{~Pa}\end{array}$ & $\begin{array}{l}\text { Temperature compensated } \\
\text { from laboratory calibration } \\
\text { over range }-13^{\circ} \mathrm{C} \text { to } 22^{\circ} \mathrm{C}\end{array}$ \\
\hline $\begin{array}{l}\text { XCQ-093 Kulite } \\
\text { pressure sensor }\end{array}$ & $+/-0.5 \%$ of full scale & $\begin{array}{ll}13,800 & \mathrm{~Pa} \\
(2 \mathrm{psi}) & \end{array}$ & $\begin{array}{l}\text { Manufacturer datasheet } \\
\text { (operating temperature range } \\
-55^{\circ} \mathrm{C} \text { to }+120^{\circ} \mathrm{C} \text {, thermal } \\
\text { shift }+/-0.016 \% /{ }^{\circ} \mathrm{C}\end{array}$ \\
\hline $\begin{array}{lll}\begin{array}{l}\text { Duck DPI } \\
\text { barometer }\end{array} & \end{array}$ & $+/-0.01 \mathrm{mbar}$ & $\begin{array}{l}35-3500 \\
\text { mbar } \\
\text { maximum }\end{array}$ & Manufacturer datasheet \\
\hline Altimeter & $+/-50$ feet & $\begin{array}{l}\text { up } r \\
10,000 \text { feet }\end{array}$ & Aircraft flight manual \\
\hline $\begin{array}{l}\text { Indicated airspeed } \\
\text { (no flaps) }\end{array}$ & $+/-2$ knots & $\begin{array}{l}\text { up to } 185 \\
\text { knots }\end{array}$ & Aircraft flight manual \\
\hline
\end{tabular}




\subsection{BULLDOG FLIGHT TEST PROGRAMME}

On completion of the Bulldog modification, a series of shakedown tests were completed over seven flights to check the performance of the fibre optic strain and pressure measurement systems. A further four flights were completed 9 months after the first set of flights. For the first six flights, a number of problems were encountered with the measurement systems, including detached speed tape, data storage loss, a faulty Kulite earth connection and a loss of the reference pressure data due to the malfunction of the Druck barometer. With flight seven and all subsequent flight tests, however, all systems operated as expected and a series of steady and dynamic manoeuvres were completed, which as defined through the Aresti system [27] included:

- Straight and level (67 knots and 100 knots IAS)

- $\quad$ Spin (left hand)

- Loop

- Stall turn (left hand)

- Slow roll (left hand)

- $\quad$ Barrel roll (left hand)

The results from flight seven are shown in Figure 7, where the series of dynamic manoeuvres are clearly present in both the pressure and strain data over a normal g-range of $-1 \mathrm{~g}$ to $+4 \mathrm{~g}$. Data rates for both the pressure and strain sensors were $2.5 \mathrm{kHz}$. In this case, the strain data from FBG 3 has been temperature corrected using FBG 5. The EFFPI pressure data has also been temperature corrected based on ISA flight conditions using a laboratory calibration, which was performed over a temperature range of $-13^{\circ} \mathrm{C}$ to $+22^{\circ} \mathrm{C}$. The strain measured by the FBG, which is related to the amount of bending of the wing, correlates well with the normal acceleration (' $\mathrm{g}$ ') that the aircraft experiences in the manoeuvre, with negative ' $\mathrm{g}$ ' giving an increasingly positive strain reading.

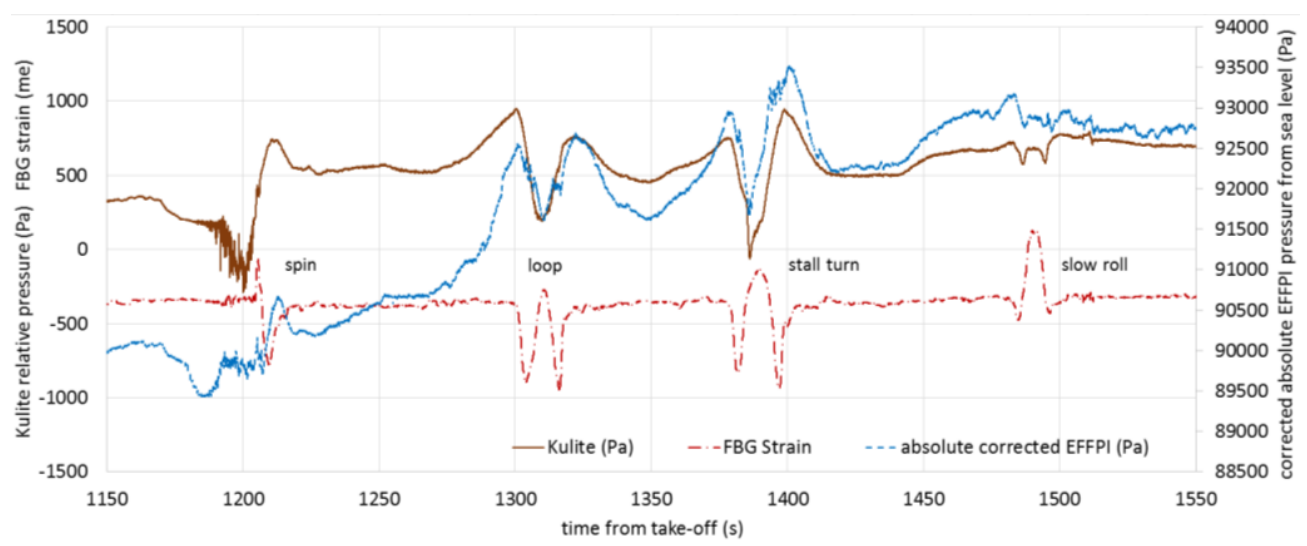

Figure 7. Typical FBG strain data, EFFPI and Kulite pressure data from a Bulldog flight test 
Comparisons of the Kulite and EFFPI pressure data, however, reveals that the measurements did not correlate as expected and shows a drift in the EFFPI measurements. Also, it is evident that the magnitude of the pressure measured by the EFFPI is significantly different to that measured by the Kulite, although the changes in pressure during a given manoeuvre match well. It was therefore suspected that the reference port for the EFFPI sensor was partially blocked during the tests. Analysis of the steady state flight data confirmed this characteristic, and although additional CFD simulations [28] have indicated an effect of the aerial and beacon on the pressures at the locations of the Kulite and EFFPI sensors, it does not account for the level of discrepancy found in the flight test data. At the time of writing, this issue with the EFFPI sensor has still not been resolved.

Follow-on flight tests included manoeuvres similar to those undertaken during flight seven and extended the g-range to $+5.1 \mathrm{~g}$. Figure 8 shows data from a wind-up-turn in the latter tests, taken from the AHRS and FBG strain sensors. The g-increments are clearly visible up to a peak normal g-load of 5.1g. This data can be applied to a simple beam model of the wing where, assuming that the wing behaves like a cantilevered beam, with a uniform load distribution $\mathrm{P}$ and a length 1 , the stress $\sigma$ at any point $\mathrm{x}$ on the beam can be found from:

$\sigma=\frac{P(l-x)^{2}}{2 Z}$

where $\mathrm{Z}$ is the section modulus of the wing. The load distribution on a wing is the lift $\mathrm{L}$, and given a load factor, $n$ and a lift over weight ratio, $\mathrm{L} / \mathrm{W}$. If the strain is $\varepsilon=\sigma / \mathrm{E}$, where $\mathrm{E}$ is the modulus of elasticity, then, the strain can be computed as:

$\varepsilon=\frac{n W(l-x)^{2}}{2 Z E}$

which indicates the strain on the wing to be proportional to the load factor $n$.

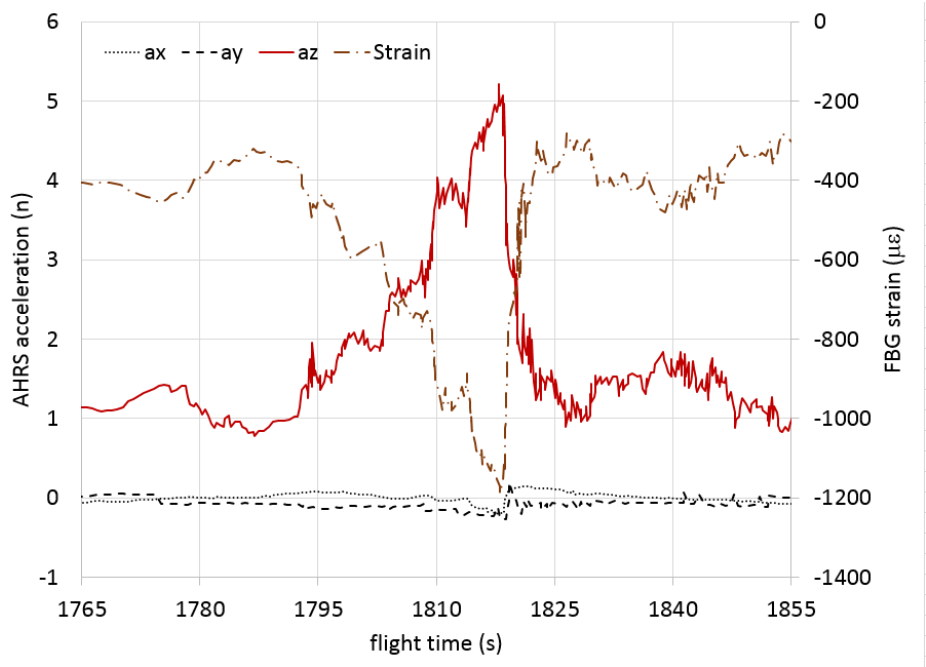

Figure 8. FBG strain and AHRS data recorded during a wind-up-turn 


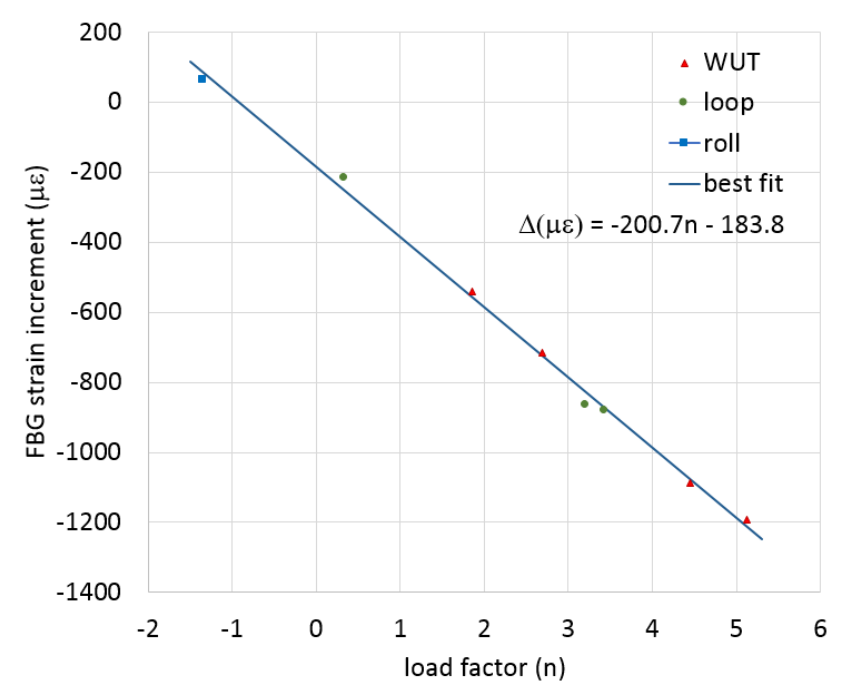

Figure 9. FBG strain load factor relationship for the Bulldog wing

Using equation 2, the data is plotted for the wind-up-turn and other dynamic manoeuvres in Figure 9, which shows the wing to behave linearly with an error of $2.1 \%$ of full scale $(+/-$ $25 \mu \varepsilon$ ). The slope of 200.7 also compares well with previous flight tests [23].

Future flight tests are planned, which will include the deployment of a modified EFFPI sensor, the addition of an air data boom, control position sensors and an ADC, as part of a major modification of the Bulldog. These future flights are expected to assist a further investigation of the sensor characteristics and performances and are expected to resolve the discrepancies between the EFFPI and Kulite sensors.

\subsection{FLIGHT TEST PROGRAMME - DISCUSSION}

Lessons learned from the aircraft certification and modification process and other related issues will be discussed in section 4.1 .

\subsection{Aircraft Certification and Modification Issues}

The $\mathrm{AIM}^{2}$ EU project started in October 2010 and the initial schedule for Cranfield University included a year of laboratory tests followed by one year of design and aircraft modification, with the first flight test planned for autumn 2012, a flight test completion by the spring of 2013. The $\mathrm{AIM}^{2}$ project was due to finish in the spring of 2014. However, the Bulldog was not certified and flight tested until July 2014 and almost all the partners in the $\mathrm{AIM}^{2}$ programme suffered from significant delays in their certification programmes, which resulted in an extension to the project to October 2014. The Cranfield flight tests occurred in July 2015. 
During the laboratory phase of the project, discussions were initiated with the Civil Aviation Authority (CAA) in the U.K. about the route to certification for the aircraft. Initially, it was thought by the CAA that the most compliant route was through EASA regulations. Unfortunately, at the time of these initial discussions, significant changes were being implemented by EASA and many new regulations were still at a consultation stage. This situation was further complicated by the Annex II nature of the Bulldog aircraft and how this status fitted into the rapidly changing EU regulatory environment. Therefore, within the first year of the project, the CAA recommendation for certification changed from an EASA approach, to an approach following national U.K. regulations. This change caused additional delays, as once the decision was made to follow national regulations, the scope for suitable modification, manufacturing and approval companies also changed. As discussed earlier, the number of companies in the U.K. with national approvals has reduced consdierably, as the EASA environment becomes dominant. Hence, only a limited number of companies could be approached for the Bulldog aircraft modification. Furthermore, the novel nature of the fibre optic modification resulted in the majority of these companies rejecting involvement with the project. This issue was one reason why a compromise was sought whereby the designs were completed by a company with EASA approvals with oversight and approval by a separate company, who held national approvals, but who did not want direct design involvement with the project.

Related to the certification, development and testing of the sensors were required in laboratories and wind tunnels before designs could be finalised for the aircraft. One of the initial issues encountered from the design company was the approach to developing instrumentation in a university laboratory environment, as against the requirements for a certified system on an aircraft. Research laboratories by their nature do not have the highly regulated environment under which aircraft must operate. Therefore, in its basic form, a workable laboratory sensor solution is unlikely to be fit for purpose in a certified aircraft. Hence, on completion of the laboratory and wind tunnel testing in the first year of the $\mathrm{AIM}^{2}$ programme, considerable iterations were required between the research team at Cranfield University and the Design Organisation to adapt laboratory designs. This process incurred inevitable delays to the overall programme which were not envisaged. The highly specialised and novel nature of the fibre optic technology also meant this was a unique design challenge not seen before by the Design Organisation and compromises had to be made with respect to application of the technology on the aircraft and the research requirement.

\subsection{Adaptation of Fibre Optic Equipment for Flight Test}

An example of this compromise with the final modification is the SmartScan Aero laser interrogation box. This box was certified to MIL-STD $810 \mathrm{G}$ and therefore greatly simplified the aircraft modification process. However, for the EFFPI system this was not the optimum sensor interrogator and therefore this compromise for the design company resulted in the requirement for significant post-processing of the EFFPI data following each flight test. 


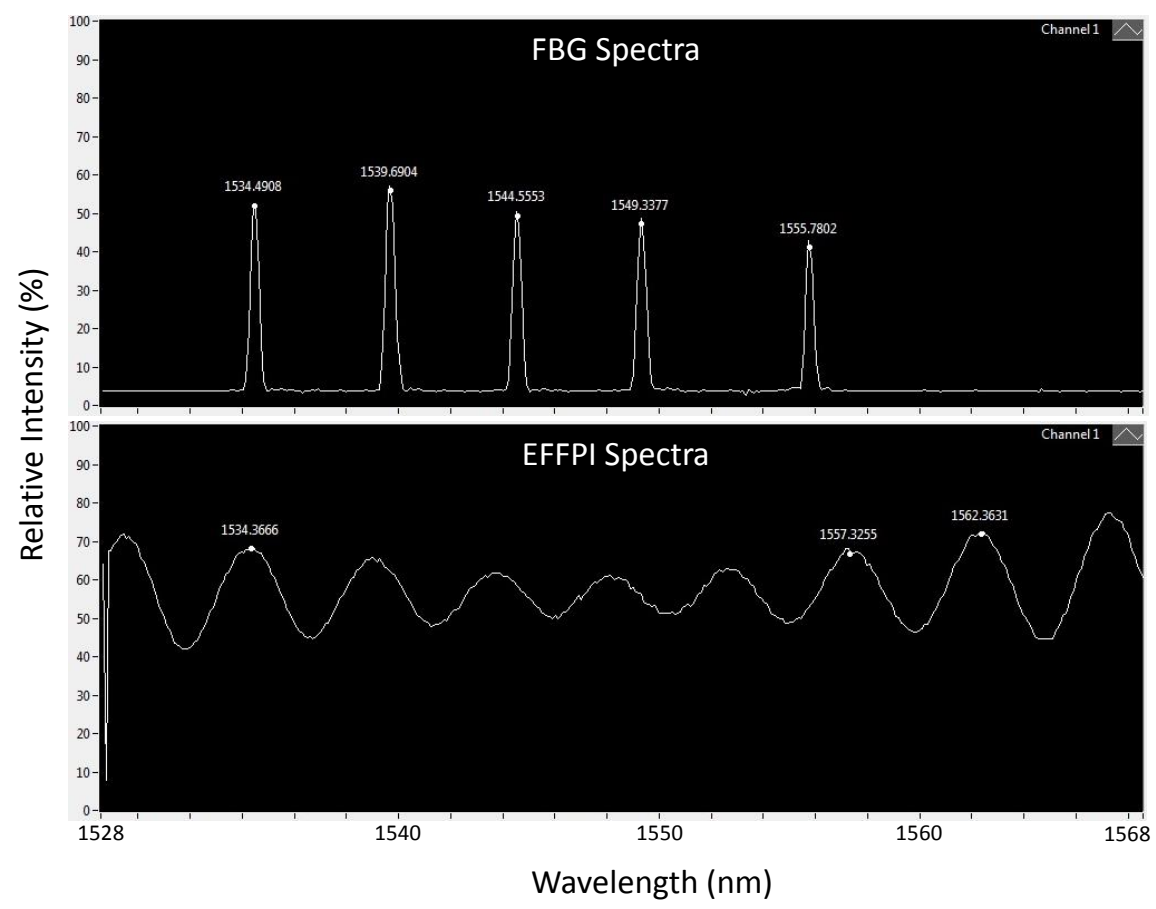

Figure 10. FBG strain and AHRS spectra recorded by the SmartScan Aero interrogator box

This post processing software had to be developed in our laboratories using Matlab and Lab View. The post-processing involved reconstruction of the EFFPI data from fragmented output data. This unsuitable signal format was the result of the SmartScan firmware being optimised for FBG processing which used a smaller signal range. To understand this problem in more detail, an example of the FBG and EFFPI spectral responses is shown in Error! Reference source not found.. In the case of the FBG, the 5 Bragg reflection can be seen, the central wavelengths of which are determined using the SmartScan firmware, with data output in the form of spectral peak wavelength calculated using a Gaussian peak-fitting algorithm. The EFFPI spectral response, however, is significantly different, with a non-Gaussian peak shape. During acquisition, the EFFPI peak movement is also significantly greater than from the FBG and this resulted in spectral peaks been lost or 'skipping' wavelength as a peak moved to the edge of the spectral range. Post-processing software reconstructed the absolute movement of peaks. The non-optimal peak-fitting algorithm also resulted in higher noise in the peak wavelength data and increased data dropout when compared to the laboratory tests of the EFFPI sensor, which used a different acquisition and processing method. Therefore, overall it was found the flight test data had a resolution of the order of 10 times less than the laboratory test which was part of the compromise of using the SmartScan Aero interrogator.

\subsection{Use of Carry-On Equipment for Flight Test}

The complex nature of the certified design resulted in further compromises over the equipment specification for the flight test. For example, both the EFFPI and Kulite sensors were relative pressure sensors, with venting ports from both sensors being fed into a common 
cockpit pseudo-ambient pressure. The computational fluid dynamic and wind tunnel tests predicted only small changes in relative pressure, of the order of several hundred Pascals over straight and level flight test conditions. Therefore, without any flight control automation in the unpressurised Bulldog, the cockpit pressure was effectively controlled by the aircraft altitude. Thus this altitude had to be held to an equivalent constant ambient pressure during the steady state straight and level manoeuvres, to allow pressure sensor assessment. Given the predicted change in the relative pressures of $100-200 \mathrm{~Pa}$, an absolute pressure sensor with a resolution of $10 \mathrm{~Pa}$ or less was specified. At the time of the modification, pressure logging boards compatible with the UEI data logging cube did not have this level of absolute pressure resolution. Larger wind tunnel calibration units produced by companies such as Druck were available, but were too bulky and would require individual certification or incorporation into a certified aircraft instrumentation box. Therefore it was decided to take a hand held barometer on-board the aircraft and to connect it to a handheld logging device, synchronised to the UEI time-stamp. The Druck DPI 740 portable barometer, with a resolution of $10 \mathrm{~Pa}$, met this requirement and this device was connected to a windows handheld PDA device. Both handheld devices were secured to the central console in the cockpit during the flight. This set-up allowed pressure logging at several Hertz throughout the flight. Synchronisation could have been improved using GPS timestamps on the UEI and PDA. However, the nature of the delays in the design and certification programme did not allow time for this and a synchronisation gross error check was completed by comparing several test parameters during the initiation of an unsteady manoeuvre or during take-off.

\subsection{Pre-flight Calibration}

In addition to using carry on devices to simplify the modification design, a simplified preflight test calibration procedure was also used to check the performance of the FBG strain system prior to the first flight test. As mentioned in section 2.4, this calibration procedure involved the use of the conventional RFSG mounted adjacent to each FBG sensor. The RFSG sensors were fitted at the same time as the fibre was secured to the wing surface. With both sensor types fitted, the wing was then loaded in the hangar through the expected strain range for the flight. The two sets of data from the RFSGs and FBGs were processed and compared, revealing a similar level of resolution and performance as found during the laboratory tests. The wire connections to the RFSGs were then removed, but the RFSG were not removed from the wing, so as not to damage the paint. The remaining short wire connectors were then taped down, with the FBGs, using 3M 425-50 speed tape, where they remain permanently. If a future calibration is required, the speed tape can be removed and the strain gauges reconnected. This approach avoided the requirement to loom the many wires connected to the RFSGs into the aircraft and to the UEI data logger, with the associated certification complexity and EMC requirements.

For the pressure based sensors, no in-situ calibration was completed as it was assumed that the laboratory tests were sufficient. Following the flight tests, a simplified data processing algorithm indicated that the EFFPI sensor was behaving normally. Unfortunately, as evidenced in the pressure data in Figure 7, the decisions not to ground test the sensors and to use a simplified processing method were unwise, as following a latter investigation of the processed data, the EFFPI sensor was found to have a suspected blocked reference port. This problem could have been isolated with an in-situ ground test of both the sensor and the postprocessing algorithms. 


\subsection{Flight Test Troubleshooting}

On completion of the certification, other issues were encountered with the Kulite sensor. Around five flight tests were required to isolate this problem, as the fault was intermittent and would not always occur with ground power on and the engine turned off. With the engine turned on, the close vicinity of the rotating propeller was an unacceptable risk for diagnosis. This limitation, along with the high levels of vibration during engine running, meant that in order to isolate the fault, a part of the wiring loom would be checked with engine off before each flight and then a new set of data recorded. On landing, the specific part of the loom and data would be checked again and conclusions drawn. Eventually, by repeating this process with each section of the loom from the cockpit to the sensor, the fault was found to be poorly connected wire at the sensor test plate. This wire was reconnected and, on flight 7, all data from the Kulite appeared stable, although the poor earthing quality of the airframe and associated white noise required the use of low pass filters to be used on the raw data from the Kulite sensor.

\subsection{FUTURE FIBRE OPTIC SENSOR APPLICATIONS}

The FBG and EFFPI fibre optic systems presented in this paper have many potential aerospace applications other than pressure and strain sensing. In section 2.1, a number of these recent applications were discussed including wing shape measurement and structural health monitoring $[15,16]$. Other adaptions of these sensors, however, are possible because the FBG and EFFPI systems have an inherent sensitivity to temperature as well as their primary measurement variables, in this case strain and pressure. This characteristic of temperature sensitivity is also present in more recent fibre methods such as fibre segment interferometry (FSI) which can measure multiple point-to-point displacements from a single fibre [29]. In this case FSI reported a temperature resolution of $0.001{ }^{\circ} \mathrm{C}$.

The standard approach to temperature compensate the primary variable is to use a 'floating' fibre sensor, such as outlined in the FBG application in this paper. This compensation fibre sensor, however, can also be calibrated for direct temperature measurement and if combinations of FBG and EFFPI sensors are used, as shown in Figure 11, a wide range of potential measurements are available including air data measurement. In the latter case, as an example, if the laboratory resolution of around $0.3 \%$ of full scale pressure is achievable using an EFFPI sensor, in conjunction with an equivalent measurement performance for temperature measurement from an FBG, airspeed measurement with a resolution better than $0.5 \%$ of full scale should be possible with a fibre based system. In this case though, there would be no static piping required, as found for standard aircraft air data systems. For strain and shape sensing, typical FSI and FBG strain resolutions are $0.2 \%-0.3 \%$ of full scale at multiple points on single fibres, which therefore offer equivalent shape measurement resolutions from aircraft structures. 


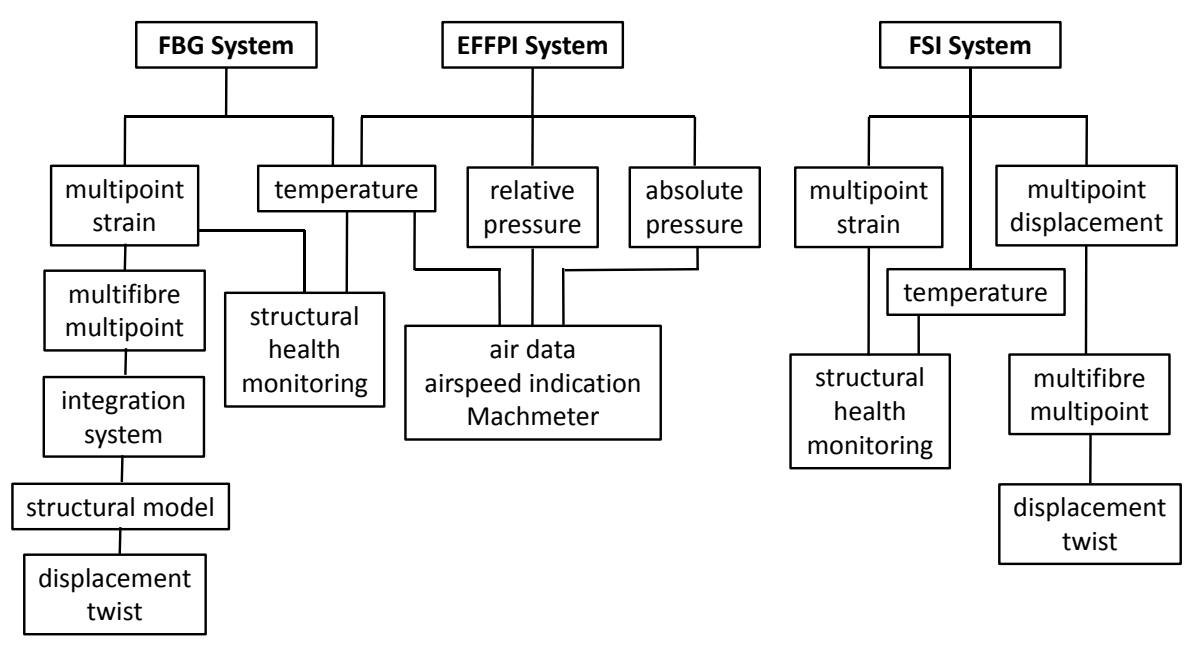

Figure 11. Potential aerospace applications for fibre optic based sensors

\subsection{CONCLUSIONS}

This paper has presented an overview of the development of a Scottish Aviation Bulldog light aircraft as a flying test bed. The aerobatic aircraft has been modified by the National Flying Laboratory Centre (NFLC) based at Cranfield University to specifically test and develop advanced sensor systems for flight test, including fibre optic based instruments. To allow unrestricted use of the aircraft, it was modified and certified under National rather than European regulations. The modification resulted in a weight penalty of around $10 \mathrm{~kg}$, but without any flight envelop restrictions.

Following certification, flight tests over the last 18 months have been completed using all of the fibre optic sensors, with a flight envelope ranging from $-1 \mathrm{~g}$ to $+5.1 \mathrm{~g}$. The fibre optic sensors tested on this platform have included a fibre Bragg grating (FBG) system for surface strain measurement and an Extrinsic Fibre Fabry-Perot Interferometer (EFFPI) static pressure sensor for dynamic static pressure measurement.

The fibre sensors exhibit a strain resolution better than $0.5 \mu \varepsilon$. Laboratory tests indicated a pressure resolution better than $0.2 \mathrm{~Pa}$ at up to sample rates of $10 \mathrm{kHz}$. Discrepancies, however, were found between the data recorded by the Kulite and EFFPI pressure sensors during the flight tests, with the resolution of the EFFPI sensor reduced by a factor of 10 . This resolution loss was due to compromises required for the data acquisition and post processing system. This discrepancy was also in-part attributed to a partially blocked static port on the EFFPI sensor. The aerodynamic interaction of protuberances adjacent to pressure sensors, such as the beacon structure, is not thought to provide a significant problem, as evidenced by CFD models of the full aircraft.

Other lessons learned during the certification process have included the requirement for the research and design teams to work closely together as early as possible during the development and design phase of the sensors. Compromises in hardware need to be found as 
research level sensor systems will not generally meet certification standards for flight. In this case, the main compromise was with the interrogator used for the EFFPI sensor. This unit required significant bespoke post-processing of the output data in Labview and Matlab, which resulted in a loss in measurement resolution. This additional processing was not required when using the laboratory interrogator box.

Future plans include the completion of further flight test research using the Bulldog, as it is currently being modified with an air data boom, control sensor positions and an ADC. This study has also highlighted a significant potential for future air data fibre optic sensors, which would give equivalent or better resolutions, when compared to current conventional air data systems, but without the requirement for static piping in the aircraft.

\section{ACKNOWLEDGMENTS}

The authors would like to acknowledge European Framework 7 funding, contract number 266107 'Advanced In-Flight Measurement 2' and EPSRC Grant number EP/H02252X/1 (For enquiries relating to access to the research data or other materials referred to in this article, please contact Cranfield University Library and Information Serviceslibrary@cranfield.ac.uk). 


\section{REFERENCES}

1. PAMADI, B.N., Performance, Stability, Dynamics and Control of Airplanes, Second Edition. AIAA, Reston, Virginia, 2004

2. COOK, M.V., Flight Dynamics Principles, Second Edition, Butterworth-Heinemann, Oxford, 2007

3. JAMESON, A., Perspective on computational algorithms for aerodynamic analysis and design. Progress in Aerospace Sciences, Vol 37, 2001, pp 197-243.

4. JAMESON, A. and Ou K., 50 Years of Transonic Aircraft Design. Progress in Aerospace Sciences, Vol 47, 2011, pp 308-318.

5. CHAPMAN, D.R., MARK, H. and PIRTLE, M.W., Computers vs Wind Tunnels in Aerodynamic Flow Simulations. Astronautics and Aeronautics, Vol 13, No 4, 1975, pp 22-30, 35.

6. .BARLOW, B., RAE JR, W.H., POPE, A., Low-Speed Wind Tunnel Testing, Third Edition, Wiley, New York, ISBN 978-81-265-2568-3 1999

7. ULBRICH N., Correlation of Wind Tunnel and Flight Test Results for a P-51B Airplane, AIAA Paper 2010-742, 48th AIAA Aerospace Sciences Meeting Including the New Horizons Forum and Aerospace Exposition 4 - 7 January 2010, Orlando, Florida, 2010, 1-31

8. MANUEL, G.S., DOTY, W.A., Flight-Test Investigation of Certification Requirements for Laminar-Flow General Aviation Airplanes, Journal of Aircraft, 28(10), 1991, pp. 652-656

9. BODEN F., LAWSON N., JENTINK H.W. KOMPENHAMS J., Advanced In-Flight Measurement Techniques, Springer-Verlag, Berlin, 2013

10. KIRMSE T. Recalibration of a stereoscopic camera system for in-flight wing deformation measurements, Measurement Science and Technology 27(5) 054001 (2016)

11. AUGERE B., BESSON B., FLEURY D., GOULAR D., PLANCHAT C. and VALLA M., 1.5 $\mu \mathrm{m}$ lidar anemometer for true air speed, angle of sideslip, and angle of attack measurements on-board Piaggio P180 aircraft, Measurement Science and Technology 27(5) 054002 (2016) 12. KOPECKI G. and RZUCIDLO P., Integration of optical measurement methods with flight parameter measurement systems, Measurement Science and Technology 27(5) 054003 (2016)

13. WUEST W., Pressure and Flow Measurement, AGARD and RTO Flight Test Instrumentation Series AGARDograph 160 (AG 160), Volume 8 (1980)

14. BOREK R. and POOL A., Basic Principles of Flight Test Instrumentation Engineering (Issue 2), AGARD and RTO Flight Test Instrumentation Series AGARDograph 160 (AG 160), Volume 1 (1994)

15. TRUTZEL M N, WAUER K, BETZ D, STAUDIGEL L, KRUMPHOLZ O, MUEHLMANN H-

C, MUELLERT T, GLEINE W, Smart sensing of aviation structures with fiber-optic Bragg grating sensors, Proc. SPIE 3986, pp. 134-143 (2000)

16. KO, W.L., RICHARDS, W.L. and FLEISCHER, V.T., Applications of Ko Displacement Theory to the Deformed Shape Predictions of Doubly Tapered Ikhana Wing, NASA/TP-2009214652, November 2009

17. CHEHURA E., JAMES S.W., TATAM R.P., LAWSON N. and Garry K.P., Pressure measurements on aircraft wing using phase-shifted fibre Bragg grating sensors, 20th International Conference on Optical Fibre Sensors, 2009, Edinburgh, 5th - 9th Oct 2009 18. RAO, Y.J., Recent progress in fibre-optic extrinsic Fabry-Perot interferometric sensors, Optical Fibre Tech., 12(3), pp. 227-237, 2006 
19. SCHMID M.J., MÜLLER M.S., KUHNLE B.A., BAUER M.W., PONGRATZ R., ALTMIKUS A., Fiber optic acoustic pressure sensor with high dynamic range and low noise, $36^{\text {th }}$ European Telemetry and Test Conference - ETC2016, 10-13 ${ }^{\text {th }}$ May 2016, Nuremberg Germany DOI 10.5162/etc2016/2.7, paper 2.7, p90-92 (2016)

20. MELTZ G., MOREY W.M. and GLENN W.H., Formation of Bragg gratings in optic fibres by transverse holographic method. Optics Letters, 14, pp823-825, 1989

21. RAO, Y.J. Recent progress in applications of in-fibre Bragg grating sensors, Opt. Laser. Eng., 31, pp. 297-324, 1999

22. NESSON S., YU M., ZHANG X., HSIEH A.H., Miniature fiber optic pressure sensor with composite polymer-metal diaphragm for intradiscal pressure measurements. Journal of Biomedical Optics 13(4), 2008

23. LAWSON N.J., CORREIA R., JAMES S.W., GAUTREY J.E. and TATAM R.P. Development of fibre optic strain and pressure instruments for flight test on an aerobatic light aircraft, European Test and Telemetry Conference June 9-11, Toulouse France, Paper 1.5 2015

24. LAWSON N.J., GAUTREY J.E., SALMON N., GARRY K.P., PINTIAU A., Modelling of a Scottish Aviation Bulldog using Reverse Engineering, Wind Tunnel and Numerical Methods, IMechE Part G, Journal of Aerospace Engineering pp7, DOI: 10.1177/0954410014524740 2014

25. Certification Specifications for Normal, Utility, Aerobatic, and Commuter Category Aeroplanes CS-23, European Aviation Safety Agency, Amendment 3, July 2012

26. Aircraft Type Certificate Datasheets, Civil Aviation Authority, U.K., November 2011

27. Aresti Power Catalogue 2016, FAl Aresti Committee, FAI (2016)

28. RIOU S., CFD and Flight Test Investigation of the Bulldog Aircraft Beacon Structure on a Pressure Sensor Plate, MSc Thesis, Cranfield University (2015)

29. KISSINGER T., CORREIA R., CHARRETT T., JAMES S. and TATAM R.., Fibre segment interferometry for dynamic strain measurements, Journal of Lightwave Technology, 34 (19) 4620-4626 (2016). 
2017

\section{Development of the Cranfield University Bulldog Flight Test Facility}

Lawson, Nicholas J.

Cambridge University Press

N.J. Lawson, R. Correia, S.W. James, J.E. Gautrey, Development of the Cranfield University

Bulldog flight test facility. Aeronautical Journal, Volume 121, Issue 1238, April 2017, pp533-552

https://dspace.lib.cranfield.ac.uk/handle/1826/11416

Downloaded from Cranfield Library Services E-Repository 